\title{
Accessible Wayfinding Testbed: Infrastructure and Components
}

\author{
Hassan A. Karimi \\ Geoinformatics Laboratory, School of Information \\ Sciences, University of Pittsburgh \\ 135 North Bellefield Avenue, Pittsburgh, Pennsylvania \\ 15260 , U.S. \\ +1412 624-4449 \\ hkarimi@pitt.edu
}

\author{
Mahdi Hashemi \\ Geoinformatics Laboratory, School of Information \\ Sciences, University of Pittsburgh \\ 135 North Bellefield Avenue, Pittsburgh, Pennsylvania \\ 15260 , U.S. \\ +1412 624-8858 \\ m.hashemi1987@gmail.com
}

\begin{abstract}
Despite considerable recent interest in research related to wayfinding and navigation of pedestrians, the needs and preferences of people with disabilities (PWDs) are not yet fully addressed. Some of still unaddressed issues are related to understanding the different mobility challenges of PWDs, while others are related to the accessibility of routes and navigation systems/services. Emergence of advanced systems and services that can assist PWDs in wayfinding and navigation calls for the development of an accessible wayfinding platform facilitating the evaluation of accessibility of indoor and outdoor routes. In this paper, we propose and present an accessible wayfinding testbed which has three components: database, accessibility index, and visualization. The database component includes networks of sidewalks outdoors and building elements indoors with accessibility elements for PWDs. The accessibility index determines the level of accessibility of each element in a network as is perceived by PWDs. The visualization component visualizes the routes, accessible and others, in a simple form allowing PWDs, urban planners, and software developers, among others, to evaluate the accessibility of the travelling environment. The paper discusses the details of the testbed and a prototype accessible wayfinding testbed.
\end{abstract}

\section{Categories and Subject Descriptors}

E.1 [Data]: DATA STRUCTURES - Graphs and networks.

G.1.6 [NUMERICAL ANALYSIS]: Optimization - Constrained optimization.

H.2.8 [DATABASE MANAGEMENT]: Database Applications Spatial databases and GIS.

I.6.0 [SIMULATION AND MODELING]: General.

I.6.3 [SIMULATION AND MODELING]: Applications.

I.6.5 [SIMULATION AND MODELING]: Model Development.

J.3 [Computer Applications] LIFE AND MEDICAL SCIENCES - Health.

Permission to make digital or hard copies of all or part of this work for personal or classroom use is granted without fee provided that copies are not made or distributed for profit or commercial advantage and that copies bear this notice and the full citation on the first page. To copy otherwise, or republish, to post on servers or to redistribute to lists, requires prior specific permission and/or a fee.

Conference'10, Month 1-2, 2010, City, State, Country.

Copyright 2010 ACM 1-58113-000-0/00/0010 ...\$15.00.

\section{General Terms}

Algorithms, Management, Measurement, Design, Experimentation, Human Factors, Theory.

\section{Keywords}

Accessible wayfinding; Accessibility database; Accessibility visualization; People with disabilities.

\section{INTRODUCTION}

Mobility is a common and routine activity performed by all people. People have different mobility needs and preferences in different environments (outdoors and indoors) and at different times. In unfamiliar environments, people often resort to wayfinding and navigation services. In this paper we make a distinction between wayfinding and navigation, where the former refers to the process of determining an optimal, or desired, route for any given trip between any pair of locations and the latter refers to the process of tracking and providing real-time guidance on a selected route. Mobility needs and preferences can be categorized based on different criteria, one of which is mode of travel including driving, riding public transportations, biking, or walking in outdoor environments. In indoor environments, wayfinding is based on walking as the main traveling mode. Wayfinding services (such as Google Maps, and Bing Maps) have become commonplace in assisting people with their mobility needs and preferences. Today, existing wayfinding services assist people with route planning using most modes of travel in many places but walking which is limited to selected locations. However, the popularity of wayfinding services for traveling by cars over time has become the impetus for the increased demand for pedestrian wayfinding services [13]. To that end, pedestrian wayfinding services have been under research and development in recent years. The major difference between outdoor pedestrian wayfinding and outdoor wayfinding based on other modes of travel is the physical (wayfinding) environment. While outdoor wayfinding requires road networks using all other modes of travel, pedestrian wayfinding requires sidewalk networks. For building outdoor pedestrian wayfinding services, systematic and automatic procedures for collecting and constructing sidewalk network databases are needed. Today, such procedures, while widely available for collecting and constructing road network databases, are scant for sidewalk network databases; see [14] for different sidewalk network data collection and construction approaches. For indoor pedestrian wayfinding services, hallway networks are needed and there are techniques for their systematic and automatic collection and construction (e.g., see[8]). 
Most pedestrian wayfinding research is focused on the general population, and in recent years research related to wayfinding and navigation of people with disabilities (PWDs) has gained the interest of researchers from different disciplines including computer and information science, rehabilitation science and technology, and robotics, to name just a few. However, current wayfinding research for PWDs is mostly a simple extension of wayfinding for the general population and is one-size-fits-all. This approach does not effectively address the wayfinding needs and preferences of PWDs in that not only different PWD groups have different requirements, each individual may have specific requirements different than the group. For example, there are specific requirements for wayfinding of wheelchair users (WC) that are different than the wayfinding requirements of people who are blind or visually impaired (B/VI). Furthermore, an individual WC user or an individual B/VI may have a set of specific needs and preferences that differ from the WC group or the B/VI group. Addressing the wayfinding requirements of PWDs requires that the wayfinding environments (outdoors or indoors) be accessible. However, while progress has been made in making the environment accessible to PWDs, there is still much work that needs to be done in understanding accessibility of pathways and how accessible wayfinding services/tools should be developed and implemented in navigation technology.

To address this gap, we propose an accessible wayfinding testbed platform for PWDs. One of the main features of the proposed accessible wayfinding testbed is that its data and functions are compliant with the national standards such as those based on the Americans with Disabilities Act (ADA), known as ADA Accessibility Guidelines (ADAAG). The accessible wayfinding testbed consists of three components: a database, an accessibility index, and a visualization.

In this paper, the accessible wayfinding testbed platform is presented and a prototype accessible way finding testbed is discussed.

\section{TESTBED PLATFORM}

In this section, we present the details of the accessible wayfinding testbed. We first define specific terms that are relevant to wayfinding of PWDs and then discuss the testbed components.

Wayfinding. The process of finding a route (optimal or desired) between a pair of locations, in outdoor or indoor environments.

Navigation. The process of tracking and providing real-time guidance on selected routes. Systems and services for navigation must be equipped with positioning sensors (e.g., GPS for outdoors and Wi-Fi for indoors).

Accessibility element. An element of the environment (outdoors, indoors) that impacts, favorably or adversely, the wayfinding of PWDs.

Connector. An element of the environment that connects the two parts of a network infrastructure (e.g., two sidewalk segments through curb cuts) or two different network structures (e.g., a ramp connecting a sidewalk segment to a building entrance).Connectors are needed by all individuals in a PWD group.

Obstacle. An element of the environment that blocks passage on a segment. Obstacles must be avoided by all individuals in a PWD group.
Maneuverable. An element of the environment that requires certain skills and care for movement. Maneuverable elements are usable based on individual's ability and preferences.

Permanent elements. The elements (connector, obstacle, maneuverable) that are fixed in the environment.

Temporary elements. The elements (connector, obstacle, maneuverable) that stay in the environment for a relatively short time.

Path. A sequence of segments (e.g., sidewalks in outdoors, and hallways in indoors) that connect the two end locations (origin and destination) in a trip.

Accessible path. A path that has a set of connectors, an empty set of obstacles, and a set of maneuverable elements.

Table 1 shows examples of accessibility elements for wayfinding of PWDs both outdoors and indoors. It is worth noting that finding accessible paths requires finding connectors, avoiding obstacles, and evaluating maneuverable. Navigating on accessible paths requires localizing movement in real-time, detecting temporary obstacles, and guiding through landmarks.

Table 1. Accessibility elements for wayfinding of PWDs.

\begin{tabular}{|c|c|c|c|c|}
\hline \multirow{2}{*}{$\begin{array}{l}\text { Accessibility } \\
\text { Elements }\end{array}$} & \multicolumn{2}{|c|}{ Outdoor } & \multicolumn{2}{|c|}{ Indoor } \\
\hline & WC & B/VI & WC & $\mathbf{B} / \mathbf{V I}$ \\
\hline Connector & $\begin{array}{l}\text { Curb } \\
\text { cuts }\end{array}$ & $\begin{array}{c}\text { Intersections } \\
\text { with audio }\end{array}$ & Elevators & $\begin{array}{c}\text { Stairs } \\
\text { with } \\
\text { handrails }\end{array}$ \\
\hline Obstacle & Steps & $\begin{array}{l}\text { Uneven } \\
\text { surfaces }\end{array}$ & $\begin{array}{c}\text { Narrow } \\
\text { hallways }\end{array}$ & $\begin{array}{c}\text { Protrusion } \\
\text { of objects } \\
\text { hanging }\end{array}$ \\
\hline Maneuverable & Slope & Steps & Carpets & Traffic \\
\hline
\end{tabular}

The proposed accessible wayfinding testbed is composed of three major components. These components are database, accessibility index, and visualization, described below.

The database component is for storing the map of the wayfinding area, finding points of interest, and computing routes, among other functions. Current spatial databases, in particular those used for wayfinding and navigation, lack accurate and up-to-date information about the accessibility of the travelling environment. Considering the differences between the physical spaces, outdoors and indoors, and different PWD criteria for finding suitable routes in each space, the accessible wayfinding testbed requires two databases: one for outdoor environments and one for indoor environments. Karimi [10] discussed the differences between the two databases for navigation by the general population, one for outdoor environments and another for indoor environments. Each database requires a specific model of pathways in the respective environment. In both databases, a graph model is suitable to represent the accessibility elements and the relationships among them. However, the graph model for outdoor wayfinding consists of nodes and links representing sidewalk segments, and the graph model for indoor wayfinding consists of nodes and links representing hallway segments. One example difference between the two models is that the nodes of the graph for outdoors are mainly intersections whereas the nodes of the graph for indoors could be entrance/exit doors, offices, and restrooms, among others.

The database component must include data and information from two perspectives. One perspective is related to PWD requirements 
for pathways (see [11]) and another is related to how standards, such as ADAAG should be used to provide accessible routes to PWDs. For the former we are creating accessible wayfinding ontologies and for the latter we are adopting the ADAAG.

The accessibility index assists in finding the optimal route, among possible ones, which is accessible for PWDs. The index is a measure of how accessible, given a set of constraints by PWD groups or individuals, a segment (sidewalks in outdoor environments and hallways in indoor environments) is. While accessibility index may conceivably be determined by taking different approaches, the most conventional approach is to find a weight for each segment of the pathway and use it in an optimization algorithm (e.g., Dijkstra's algorithm [6]) to find the most accessible routes. Accessibility index (segment weight) in the testbed must take into account a set of standards, such as those in the ADAAG.

The visualization component is for analyzing the accessibility of the environment and the routes that are feasible for PWD groups and/or individuals. The computed routes in the testbed are visualized in form of heatmaps. Different people with different interests and perspectives can utilize these heatmaps. Urban planners, analyzing smart cities, can use such heatmaps to evaluate and analyze the accessibility of the environment (outdoor, indoor) and find the accessibility gaps. Software developers can use these heatmaps to design suitable services, such as wayfinding and navigation, for PWDs. PWDs can utilize these heatmaps to evaluate the travelling environment for their own mobility activities and find the routes that are feasible and they are comfortable to take or even decide which area is a better choice to live or work. To communicate the produced heatmaps to PWDs, for both outdoor and indoor wayfinding activities, the visualization component also includes an interactive web map service.

\section{ACCESSIBILITY WAYFINDING TESTBED PROTOTYPE}

\subsection{Data Models and Database}

Ontologies for wayfinding and navigation have been investigated by some researchers. Current ontologies for wayfinding, some of which specifically for PWDs, do not consider the different wayfinding requirements of different PWD groups and are not based on the widely established standards. Table 2 shows a summary of proposed ontologies for pedestrian wayfinding and navigation. As shown in this table, while currently there are ontologies that address some aspects of accessible wayfinding of PWDs, there is a gap in research in that none is generalized and comprehensive enough to address all mobility challenges faced by PWDs in different environments.

Table 2. Ontologies for pedestrian wayfinding and navigation [2].

\begin{tabular}{|c|c|c|c|c|c|}
\hline Name & Purpose & Use & $\begin{array}{c}\text { Environmental } \\
\text { Features }\end{array}$ & $\begin{array}{l}\text { Definition of } \\
\text { Accessibility }\end{array}$ & $\begin{array}{c}\text { Source of } \\
\text { Knowledge }\end{array}$ \\
\hline $\begin{array}{l}\text { Walk } \\
\text { Ontology } \\
\text { [21] }\end{array}$ & $\begin{array}{l}\text { To create language and } \\
\text { direction independent } \\
\text { navigation instructions }\end{array}$ & $\begin{array}{l}\text { To translate instructions into } \\
\text { new languages and reverse the } \\
\text { direction of instructions }\end{array}$ & Landmarks & $\begin{array}{l}\text { Not focused } \\
\text { on } \\
\text { accessibility }\end{array}$ & Walk guides \\
\hline $\begin{array}{l}\text { Landmark } \\
\text { Ontology for } \\
\text { Hiking } \\
\text { [22] }\end{array}$ & $\begin{array}{l}\text { To formally represent } \\
\text { landmarks for hiking }\end{array}$ & $\begin{array}{c}\text { To automate use of landmarks } \\
\text { in the Terrain Navigator } \\
\text { application }\end{array}$ & $\begin{array}{l}\text { Landmarks, hiking } \\
\text { trails }\end{array}$ & $\begin{array}{c}\text { Focus on older } \\
\text { adults (limited } \\
\text { walking, using } \\
\text { wheelchair) }\end{array}$ & $\begin{array}{l}\text { Interviews, } \\
\text { empirical study } \\
\text { with hikers, } \\
\text { map legends }\end{array}$ \\
\hline $\begin{array}{c}\text { Pedestrian } \\
\text { Ontology } \\
{[\mathbf{5 , 3}, \mathbf{4}]}\end{array}$ & $\begin{array}{l}\text { To define pedestrian } \\
\text { information needs and } \\
\text { data specifications }\end{array}$ & $\begin{array}{c}\text { To identify the core elements } \\
\text { of route instructions for } \\
\text { pedestrians }\end{array}$ & $\begin{array}{l}\text { Conceptual: distance, } \\
\text { landmarks, map. } \\
\text { Physical: streets, } \\
\text { buildings, green areas }\end{array}$ & $\begin{array}{c}\text { None: } \\
\text { adaptive } \\
\text { services for } \\
\text { PWDsare } \\
\text { considered as } \\
\text { future work }\end{array}$ & $\begin{array}{c}\text { Existing car } \\
\text { navigation } \\
\text { services and } \\
\text { literature on } \\
\text { human } \\
\text { cognitive maps } \\
\text { for pedestrians }\end{array}$ \\
\hline $\begin{array}{c}\text { Indoor } \\
\text { Navigation } \\
\text { Ontology } \\
\text { (INO) } \\
\text { [1] }\end{array}$ & $\begin{array}{l}\text { To describe navigation } \\
\text { paths }\end{array}$ & $\begin{array}{l}\text { To enable reasoning for route } \\
\text { selection }\end{array}$ & $\begin{array}{l}\text { Hallway paths, } \\
\text { points-of-interest, } \\
\text { obstacles }\end{array}$ & $\begin{array}{c}\text { Based on } \\
\text { physical and } \\
\text { perceptive } \\
\text { capabilities of } \\
\text { individual } \\
\text { users }\end{array}$ & Unknown \\
\hline $\begin{array}{l}\text { ONALIN } \\
{[\mathbf{7 , 1 2}]}\end{array}$ & $\begin{array}{l}\text { To model indoor } \\
\text { networks and features }\end{array}$ & $\begin{array}{l}\text { To provide routes within a } \\
\text { building that meet the special } \\
\text { needs and preferences of } \\
\text { individuals }\end{array}$ & $\begin{array}{l}\text { Hallway paths, } \\
\text { points-of-interest, } \\
\text { transitions }\end{array}$ & $\begin{array}{c}\text { Based on } \\
\text { ADAAG } \\
\text { criteria - focus } \\
\text { on mobility } \\
\text { and vision } \\
\text { communities }\end{array}$ & $\begin{array}{l}\text { ADAAG } \\
\text { Standards }\end{array}$ \\
\hline $\begin{array}{l}\text { Ontology for } \\
\text { Structure } \\
\text { Description } \\
\text { [9] }\end{array}$ & $\begin{array}{l}\text { To describe a structure } \\
\text { (building) }\end{array}$ & $\begin{array}{l}\text { To allow users to point a } \\
\text { device at an object and receive } \\
\text { a semantic description }\end{array}$ & $\begin{array}{l}\text { Floor, wall, room, } \\
\text { building }\end{array}$ & $\begin{array}{l}\text { None - even } \\
\text { though target } \\
\text { population is } \\
\text { the blind } \\
\text { community }\end{array}$ & Unknown \\
\hline
\end{tabular}

We have developed the first version of the ontologies in this prototype, one set for outdoor accessible wayfinding and another set for indoor accessible wayfinding. Figures 1 and 2 show our accessible wayfinding ontologies for outdoor and indoor environments in the prototype which are based on the ADAAG. In this first version, these ontologies are for general PWDs and have 
B/VI.

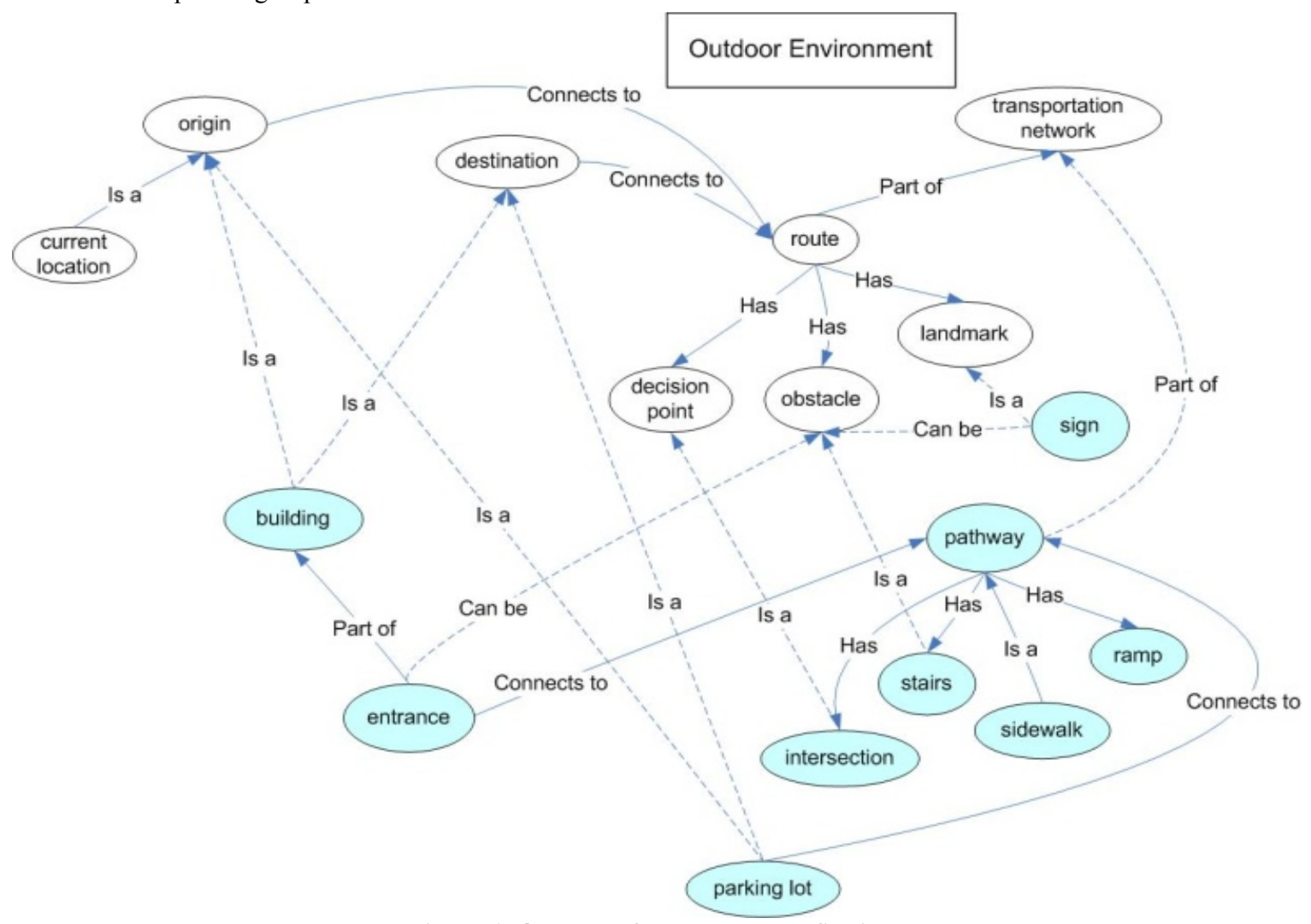

Figure 1. Ontology for outdoor wayfinding. 


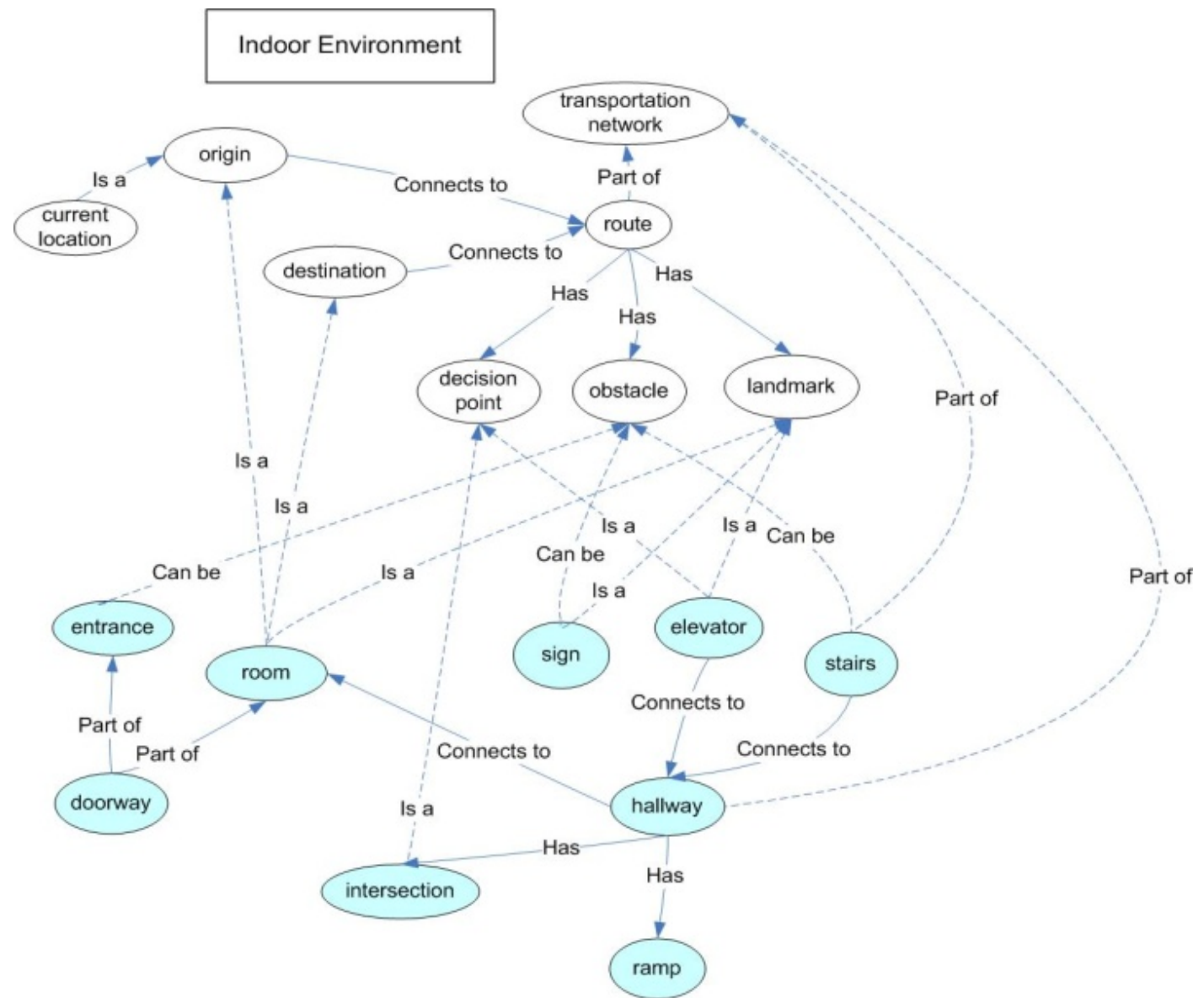

Figure 2. Ontology for indoor wayfinding.

These ontologies, which incorporate both PWD and standards perspectives, are used to design the database component of the prototype accessible wayfinding testbed. In other words, the ontology in Figure 1 can be used to determine which components of the outdoor environment are of interest to PWDs, how the outdoor environments should be modeled and which components should be considered in the database. Figure 3 shows a map of the accessible sidewalk network of the University of Pittsburgh's

main campus based on these ontologies in the prototype. This map database was manually collected and is of high quality (see [18]), which is suitable as a testbed. The spatial components in this figure are in accordance with the elements of the ontology in Figure 1.Figure 4 shows the plan of the first floor in a building of the University of Pittsburgh's main campus and its corresponding network developed for wayfinding. This figure is modeled based on the elements of the ontology in Figure 2. 


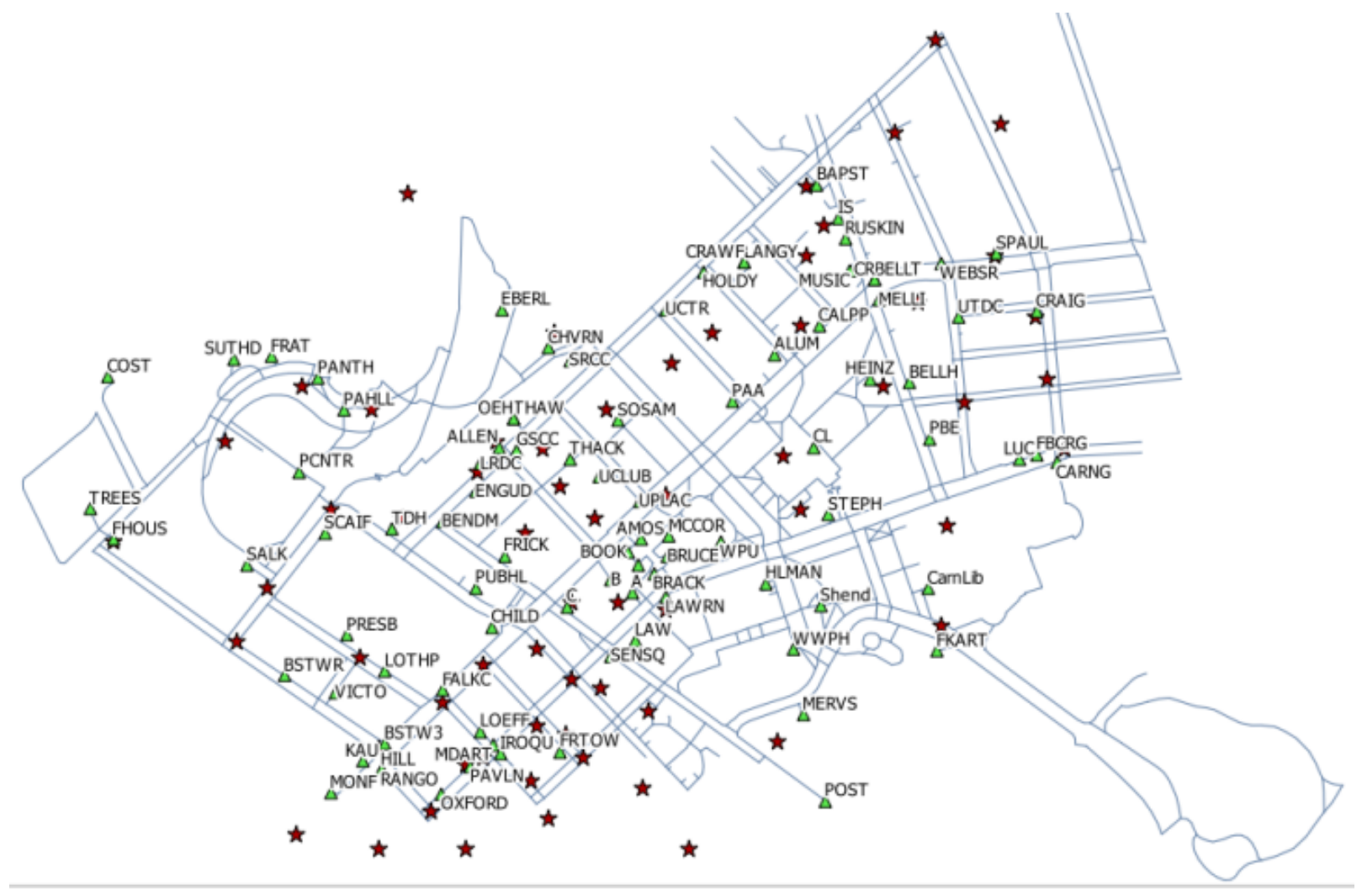

Figure 3. A map of the accessible sidewalk network of the University of Pittsburgh's main campus.

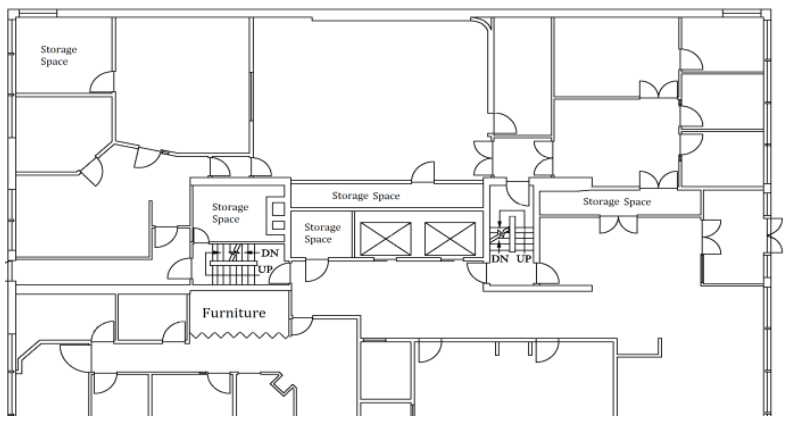

(a) Plan

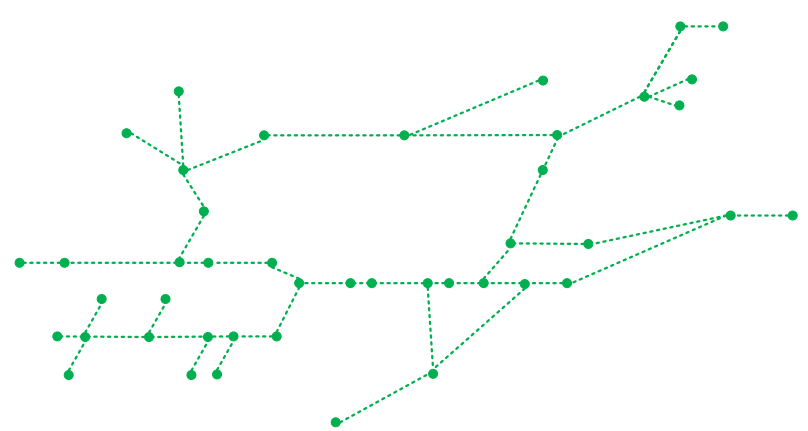

(b) Network

Figure 4. Plan of the first floor of a building and the corresponding accessible network for wayfinding.

\subsection{Accessibility Index}

The accessible wayfinding testbed prototype includes accessible indices for both outdoor and indoor environments. For outdoor wayfinding, the prototype testbed includes a linear weight model developed by Tajgardoon and Karimi [23] (see Equation 1). In this equation, W1 to W8 are the weights for the parameters, such as slope and steps. The values for these weights are expected to be provided by the users. Kasemsuppakorn and Karimi [19] developed a fuzzy logic model and conducted a study with subject wheelchair users where each user indicated a value (within a range) for each parameter based on his/her needs and/or preferences [20]. For indoor wayfinding, Equation 2 was used in the prototype and the term accessibility in this equation is the same as accessibility index.
SegmentImpedanceScore

$$
\begin{aligned}
& =\mathrm{W} 1 \times \frac{\text { Slope }}{\text { Max(slope })}+\mathrm{W} 2 \times \frac{\text { steps }}{\mathrm{Max}(\text { steps })} \\
& +\mathrm{W} 3 \times \frac{\text { length }}{\text { Max(length })}+\mathrm{W} 4 \times \frac{\text { crosswalk }}{\text { Max(crosswalk) }} \\
& +\mathrm{W} 5 \times \frac{\text { traffic }}{\text { Max(traffic })} \\
& +\mathrm{W} 6 \times \frac{\text { surfacetype }+ \text { surfacecondition }}{\text { Max(surfacetype }+ \text { surfacecondition })} \\
& +\mathrm{W} 7 \times\left(1-\frac{\text { width }}{\text { Max(width })}\right)+\mathrm{W} 8 \times(1 \\
& \left.-\frac{\text { landmark }}{\text { Max(landmark }}\right)
\end{aligned}
$$


SegmentImpedanceScore

$$
\begin{aligned}
& =(\text { length } \times \text { Accessibility of hallway }) \\
& +(\text { number of stairs } \\
& \times \text { Accessibility of stairs }) \\
& + \text { (length } \times \text { Accessibility of ramp }) \\
& + \text { (Accessibility of elevator }) \\
& + \text { (Accessibility of doorway })
\end{aligned}
$$

\subsection{Visualization}

Using the database and the accessibility indices developed in the prototype, we conducted a series of simulations to create heatmaps for both outdoor and indoor accessible wayfinding. Figure 8 shows the heatmaps using the accessible sidewalk network of the University of Pittsburgh's main campus. These heatmaps are the results of simulating different scenarios for WC users (Figure 8(a)) and individuals who are B/VI (Figure 8(b)) using the linear weight model in Equation 1. In these heatmaps the segments marked in green are considered comfortable, those marked in yellow are considered semi-comfortable, those marked in red are considered uncomfortable, and those marked in black are considered impassible. The range of an impedance score on each segment (obtained from Equation 1) is divided into three categories. Each category indicates how a segment is perceived by a group or individual for wayfinding.

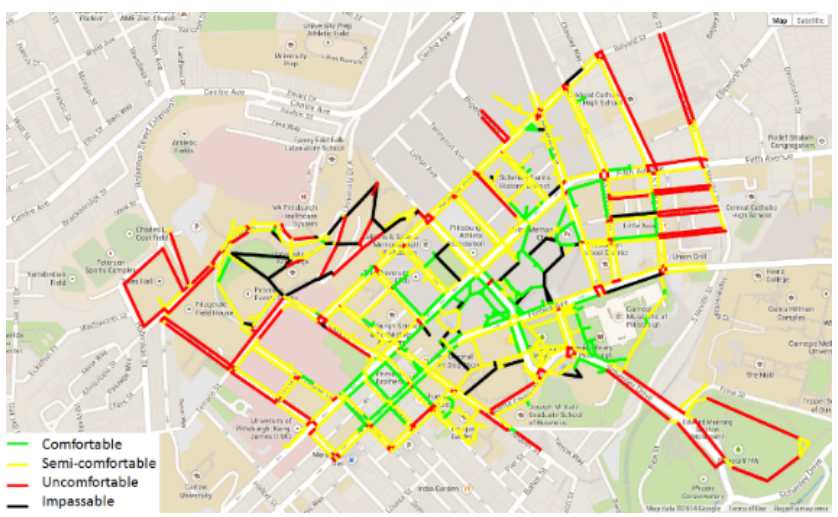

(a) Heatmap for WC users.

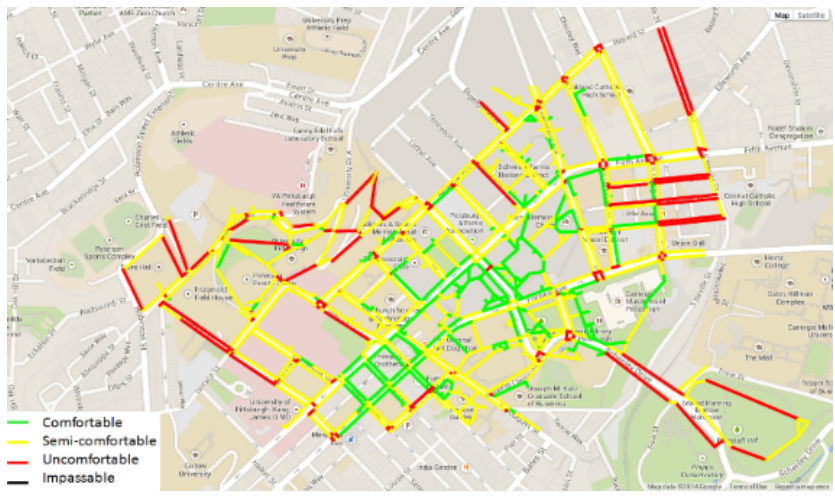

(b) Heatmap for individuals who are B/VI.

Figure 8. Heatmaps for PWDs: (a) heatmap for WC users and (b) heatmap for individuals who are B/VI [23]

Figure 9 shows the heatmap for accessible routes in a building of the University of Pittsburgh's main campus. Colors in this figure have the same meaning. Red means not accessible, green means easily accessible and yellow means hardly accessible.

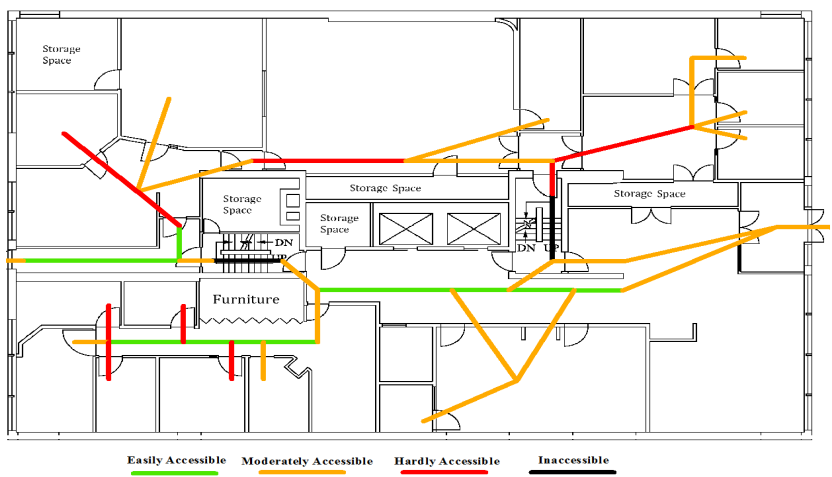

Figure 9. Heatmap of the accessible routes in the first floor of a building.

The visualization component of the prototype includes an interactive web map service, called Personalized Accessibility Map (PAM) $[15,17,16]$. In this prototype version, PAM only features outdoor wayfinding activities using the sidewalk in the University of Pittsburgh's main campus (see Figure 3). PWDs and other travelers can utilize the prototype PAM to locate accessible entrances of campus buildings, locate locations of interest (e.g., restaurant and bank), find shortest paths between campus buildings, request personalized optimal paths between campus buildings (e.g., a path personalized for wheelchair users) based on their requirements, and find and locate university transit shuttles for travelling between campus locations. Figure 10 shows an example of PAM's web map interface.

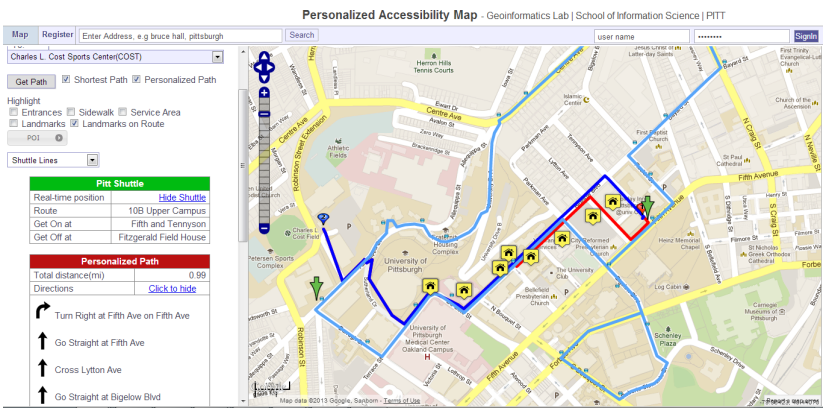

Figure 10. PAM's user interface.

\section{SUMMARY}

The necessity of a testbed capable of storing the elements of the indoor and outdoor traveling environments, assessing the accessibility of each element in the network, and visualizing the environment is highlighted in this paper. In this paper, an accessible wayfinding testbed is proposed. The testbed includes three components: database, accessibility index, and visualization. The database component is proposed to be designed based on integrating two sets of ontologies, one set to understand the wayfinding and navigation requirements of PWDs, and another set to understand the accessibility of the travelling environment. The accessibility index component needs to be developed for outdoor and indoor environments and by taking different modeling approaches. The visualization component is to communicate the accessibility of the travelling environment and accessible routes to PWDs, urban planners, and software developers, among others. A prototype of the proposed accessible wayfinding testbed was developed and the details of each component are discussed in this paper.

\section{REFERENCES}


1 Anagnostopoulos, C., Vassileios, T., Panayotis, K., and Stathes, P. H. OntoNav: A Semantic Indoor Navigation System. In 1st Workshop on Semantics in Mobile Environments (SME'05) ( 2005).

2 Benner, J. G. and Karimi, H. A. Accessible Wayfinding Ontologies for People with Disabilities. In Proceedings: Accessible Wayfinding Using Web Technologies Symposium. Online Symposium ( 2014).

3 Corona, B. and Winter, S. Approaches to an Ontology for Pedestrian Navigation Services. 2001 b.

4 Corona, B. and Winter, S. Datasets for Pedestrian Navigation Services. In Angewandte Geographische Information verarbeitung. Proceedings of the AGIT Symposium (Salzburg, Germany 2001c), 84-89.

5 Corona, B. and Winter, S. Guidance of Car Drivers and Pedestrians. Institute for Geoinformation, Technical University of Vienna. Vienna, Austria, 2001a.

6 Dijkstra, E. W. A note on two problems in connexion with graphs. 1959.

7 Dudas, P., Ghafourian, M., and Karimi, H. A. ONALIN: Ontology and Algorithm for Indoor Routing. In Tenth International Conference on Mobile Data Management: Systems, Services and Middleware (2009), 720-725.

8 Durrant-Whyte, H. and Bailey, T. Simultaneous localization and mapping: part I. Robotics and Automation Magazine, IEEE, 13, 2 (2006), 99-110.

9 Jacquet, C., Bourda, Y., and Bellik, Y. A Context-Aware Locomotion Assistance Device for the Blind. In In People and Computers XVIII - Design for Life, Proceedings of HCI 2004 ( 2005), 315-328.

10 Karimi, H. A. Universal Navigation on Smartphones. Springer, 2011.

11 Karimi, H. A., Dias, M. B., Pearlman, J., and Zimmerman, G. Wayfinding and Navigation for people with Disabilities Using Social Navigation Networks. Transaction son Collaborative Computing, 14, 2 (2014).

12 Karimi, H. A. and Ghafourian, M. Indoor Routing for Individuals with Special Needs and Preferences. Transactions in GIS, 14, 3 (2010).

13 Karimi, H. A., Jiang, M., and Zhu, R. Pedestrian Navigation Services: Challenges and Current Trends. Geomatica, 67, 4 (2013), 259-271.
14 Karimi, H. A. and Kasemsuppakorn, P. Pedestrian Network Map Generation Approaches and Recommendation. International Journal of Geographical Information Science, 27, 5 (2013), 947-962.

15 Karimi, H. A., Zhang, L., and Benner, J. G. Personalized Accessibility Map (PAM): A Novel Assisted Wayfinding Approach for People with Disabilities. Annals of GIS, 20, 2 (2014), 99-108.

16 Karimi, H. A., Zhang, L., and Benner, J. Personalized Accessibility Maps (PAMs) for Communities with Special Needs. In The 12th International Symposium on Web and Wireless Geographical Information Systems (W2GIS 2013) (Banff, Canada. 2013), Best Paper Award.

17 Karimi, H. A. and Zimmerman, G. Personalized Accessibility Location Services (PALS) Cloud for Individuals With Sensory And Physical Disabilities. In Rehabilitation Engineering and Assistive Technology Society of North America (Bellevue, WA 2013).

18 Kasemsuppakorn, P. and Karimi, H. A. Data Requirements and Spatial Database for Personalized Wheelchair Navigation. In 2nd International Convention on Rehbilitation Engineering \& Assistive Technology (Bangkok, Thailand 2008).

19 Kasemsuppakorn, P. and Karimi, H. A. Personalized Routing for Wheelchair Navigation. Journal of Location Based Services, 3, 1 (2009), 24-54.

20 Kasemsuppakorn, Piyawan, Karimi, Hassan A., Ding, Dan, and Ojeda, Manoela A. Understanding route choices for wheelchair navigation. Disability and Rehabilitation: Assistive Technology, 0 (2014), 1-13.

21 Paepen, B. and Engelen, J. Using a Walk Ontology for Capturing Language Independent Navigation Instructions. In Proceedings of ELPUB'06 Conference on Electronic Publishing ( 2006), 187-195.

22 Sarjakoski, T., Kettunen, P., Halkosaari, H., Laakso, M., Rönneberg, M., and Stigmar, H. Landmarks and a Hiking Ontology to Support Wayfinding in a National Park During Different Seasons. In Cognitive and Linguistic Aspects of Geographic Space, Lecture Notes in Geoinformation and Cartography (Berlin, Heidelberg 2013), Springer.

23 Tajgardoon, A. and Karimi, H. A. Simulating and Visualizing Sidewalks Accessibility for Wayfinding of People with Disabilities (under review). (). 